\title{
A Study of CATTI Teaching Participation in Translation Specialist Cultivation of English Majors in China
}

\author{
ZHANG Ying-xian \\ South China Business College, Guangdong University of Foreign Studies, Guangzhou, China
}

\begin{abstract}
China Accreditation Test for Translators and Interpreters (CATTI) is the most authoritative accreditation for translation and interpretation qualification in China. It is an important task to improve English majors' translating and interpreting ability in specialist cultivation. By applying CATTI level 3 to translation course teaching for English majors, this paper aims to explore CATTI participation in teaching practice from the perspective of teaching contents, teaching forms, and teaching methods so as to realize close integration between CATTI and cultivation of English majors in translation for training more qualified translators and interpreters.
\end{abstract}

Keywords: CATTI teaching participation, translation specialist cultivation, English translation training of English majors

\section{Introduction}

CATTI is the abbreviation of the China Accreditation Test for Translators and Interpreters. On March 21, 2003, the Ministry of Personnel decided to implement a national unified examination for translators and interpreters. The translation profession will be formally incorporated into the national vocational qualification examination series. How to improve the translation ability of English majors is an important task for colleges and universities in translation cultivation of specialists. The author thinks that it is an effective way to integrate CATTI teaching into cultivation of English majors.

\section{The Importance of CATTI to Translation Cultivation of English Majors}

CATTI is the most authoritative professional qualification certification of translation in China. There is some misunderstanding that if you understand English, you can do translation. In fact, there is a clear difference between the training mode of translation specialists and that of foreign language learners. Only understanding a foreign language is not equivalent to a qualified translator, as translation specialists need to have specialized professional skills and knowledge, especially, more translation practice. For example: good professional ethics, the ability of bilingual translation, proficiency in the cultural background and language laws of both Chinese and foreign languages, extensive professional knowledge, etc. (Yang, 2011, p. 81). The degree of specialization in

\footnotetext{
Acknowledgements: This thesis is supported by CATTI Participation Model of Translation Teaching and its Effect on the Cultivation of Translation Training of English Majors (Grant No. 45, 2016), project attachment Corpus-Establishment and Application of Translation Practice to the Key Discipline of Guangdong Province (Grant No. 1, 2017), and The Association Project of Comparative Study of English and Chinese in the New Era (Grant No. 2018).

ZHANG Ying-xian, professor, South China Business College, Guangdong University of Foreign Studies, Guangzhou, China.
} 
translation is increasing in China today under the background of the professional division of labor; and the construction of school curriculum system needs to be related to the demands of the society (Dong, 2013, p. 71). The perfect combination of CATTI and English major translation course teaching is the important way that colleges and universities should pay attention to and that will help train more and more translation specialists.

\section{Translation Qualification Examination and Translation Teaching}

In accordance with the interim provisions of the Ministry of Personnel on the examination of professional qualifications for translation, it is conducted under the guidance of the Ministry of Personnel and organized and administered by Chinese Foreign Language Publishing and Distribution Institutions. The exam is divided into three levels, level 1, 2, and 3 of interpretation and translation and the subjects are classified as comprehensive competence and translation practice. In July 2003, the Committee of English experts on English translation qualification (proficiency) examination came to agreement and from December 6 to 7, 2003, it was the first time to conduct level two and three of English interpretation and translation examinations in China. At present, the examinations of CATTI level 2 and 3 are suitable for English majors according to the students translation ability. How to apply CATTI into the translation course of English majors and optimize the teaching of translation courses is of great practical significance to the cultivation of English translation professionals.

\section{Concept of CATTI Participation in Translation Teaching}

CATTI participation in translation teaching refers to the integration of the content of CATTI examination into undergraduate translation teaching. The teaching process is not intensive training, but the teaching contents, methods, and evaluation methods have been changed in cooperative teaching, CATTI task-based teaching to promote translation teaching goals.

CATTI, the national translation professional qualification test is a national translation professional certificate examination which is catering to the translation market nowadays. CATTI level 3 translation examination requires candidates with the reading comprehension ability of English articles with common writing styles, being able to use general translation strategies and techniques for bilingual and cultural transformation. The CATTI level 3 exam covers business, politics, finance, people's livelihood, economy, diplomacy, culture, environmental protection, hygiene, and tourism, etc. The CATTI test mainly investigates translation levels of translation specialists, integrates CATTI into the translation teaching of English majors, and cultivates the students ability in translation practice and professional humanistic accomplishment. The significance of the examination is as follows:

The combination of CATTI examination and translation course teaching for English majors. CATTI is the separation from translation education plan of foreign language teaching and the development of translation education in a hierarchical and systematic management. The purpose of the CATTI level 3 is to test whether the candidates have translation ability to the level of the quasi-professional interpreter according to CATTI level examination. The unique form and content of qualification examination are related to the training goal of college and university undergraduates in essence (Feng, 2007, pp. 53-55). In English translation course, the combination with the content of CATII examination is beneficial to improvement the ability of students' translation skills and practice, which can help students obtain translation professional qualification certificate by taking CATTI examination, thus enhancing the students' employment competitiveness. 
The combination of CATTI examination and translation market demands. In order to promote the national translation qualification examination to serve the undergraduate translation teaching, it is an effective way to change some translation teaching methods for the market demand, with the the realization of the combination of the education of profession and undergraduate course teaching, and the reform of translation teaching for training more and more qualified translation specialists.

The combination of CATTI examination and competitiveness of translation professional accomplishment. The examination of professional ethics is an inevitable requirement for standardization of the management of the translation industry. By taking part in the CATTI examination, we can improve the practical ability of English majors in interpreting and translating, and cultivate their translation professional and humanistic quality with more competitive in employment in the market.

\section{Analysis of the Practice of CATTI Participation in Translation Course Teaching}

The CATTI participation in translation course teaching, by combining the CATTI level 3 with the undergraduate education of translation, adjusts the teaching objectives, contents, methods, and evaluation methods of translation teaching, so as to promote students`consciousness of importance and requirements of CATTI, familiar with the process and content of the CATTI level 3, meanwhile it helps them broaden their knowledge and master translation skills and improve students' cultural qualities and abilities shown as the followings: Translation abilities including students' bilingual language and cultural transformation ability, strategy ability, tool ability; ability of instrument application referring to the application of the theory in solution of translation problems such as speed translation process; critical thinking ability; and the ability to search network resources. Interpretation ability refering to students' bilingual information listening and manipulating skills, interpretation skills, language communication skills, adaptability, pychological quality, and so on.

The translation practical reference of CATTI level 3, which serves as the practical material in translation course teaching, is an important auxiliary material for English major translation learning. In translation practice, translation theory, English and Chinese language contrast and translation skills are analyzed, so that the teaching materials of CATTI integrated competence course can be used as students' independent learning materials. We must pay attention to the combination of the three aspects, that is, teaching content, teaching methods, and teaching form for the teaching goal with the goal of CATTI level 3 examination. Through the integration of translation theory and practice, students' speculative thinking and translation practice ability can be cultivated, their autonomous learning ability and the ability of communication and cooperation improved, so as the translation professional accomplishment.

\section{Elaborate Course Teaching Content}

The course teaching content is combined with the target content of CATTI level 3 examination, particularly with the consideration of the difficulties of the application, as well as the permission of the course time. The basic courses of English major`s should be finished in the first five terms, according to the outline of CATTI examination requirements, which is above the language level of foreign language major undergraduates, including comprehensive and translation practical ability. Therefore, attention should be paid to the connection between the teaching content of translation course of English major`s and CATTI level 3 teaching material in which the translation teaching should cover the comprehensive language knowledge and translation practice 
training, such as vocabulary, reading comprehension, grammar, cloze test, and so on, while the interpretation part involves English listening comprehension and practical training in interpreting. Therefore the textbook of CATTI level 3 is an effective supplement to undergraduate translation teaching and learning with the important attachment to translation knowledge and skills, according to the students' language ability and translation ability at this stage.

The main contents of the translation course teaching are based on the requirements of the CATTI level 3 for translation competence with the training of comprehensive translation ability and translation practice ability. In addition, computer aided translation courses are offered for English majors. Nowadays, it is high necessary for students to master translation tools and related techniques, which has become a must for applied translation specialists. Only translators who are proficient in translation technology can be regarded as highly qualified professional translators or professionals. How to effectively apply computer-assisted translation technology to the training of college English translation specialists, and how to realize the connection between college translation specialist training and market demand have become problems for the urgent solusion. Computer-assisted translation course is the trend of English major translation specialist training. Therefore, it is of great significance to set up computer-assisted translation courses to improve students' translation level and to cultivate translation specialists.

\section{Setting up the Reasonable Teaching Model}

The model of CATTI participation in course teaching adopts the combination of formative evaluation and summative evaluation, which includes CATTI level 3 in the evaluation of translation teaching. And it is mainly based on practice of the students' trilogy: pre-translation, mid-translation, post-translation, and necessary to prepare well before translation, to achieve the quality of translation in the middle, and to check carefully after translation. The teaching process is not only intensive training, but cooperative teaching, task-based teaching with the promotion of students' thinking and communication, and the improvement of the students' ability in analyzing and solving translation problems. The Moodle network assistant platform and the WeChat public platform also play very important role in classroom teaching after class so as to strengthen students' translation and interpretation ability by making full use of their extracurricular time. At the same time, the CATTI level 3 in course teaching helps the students increase a perceptual understanding of the CATTI translation process, skills and speed as well as the psychological quality requirements of the examinees, improvement of translation speed and quality.

\section{Reform of Teaching Methods}

CATTI participation in course teaching is a kind of teaching activity with some kinds of teaching methods, such as discussion, games, demonstrations, exercises, experiments, and so on. (Shao, 2009, p. 99) Methods of cooperative learning in translation course teaching for English majors adapts different teaching methods as for the requirment of different teaching contents, such as situational simulation testing and cooperative training in interpreting teaching, etc., and in the course of translation, there are also some important methods which can achieve fine results, namely, translation comparative method, case teaching method, CAT teaching method, and so on. Special attention should be paid to the training method of translation and interpretation practice, because the test of translation practice is difficult in CATTI examination, so examinees have to strengthen more practice, 
trying to gain a good result in the training of translation practice.

\section{The Key Points to the Implementation of CATTI Oriented Teaching}

CATTI participation in translation course teaching cannot marely follow the CATTI textbook module for intensive training teaching. Only by integrating CATTI teaching into the translation course teaching of undergraduate education, should we design teaching objectives, contents, methods, and evaluation methods to avoid the misunderstanding of examination-oriented education. By adopting the student-centered teaching method and some modern technology, we can overcome the disadvantages of the traditional translation teaching mode and fully arouse the students' enthusiasm for learning and participating in CATTI examination.

In the course of implementation of CATTI participation in course teaching, so as to achieve good teaching results, we must first do some investigation of teaching status and teaching practice results: (1) The investigation of teaching status: Mapping the translation ability of English majors in college and university undergraduates in the form of CATTI level 3, the students' translation ability is estimated according to the results of the examination. (2) The investigation of the results of teaching practice: The investigation of the result of CATTI participation in course teaching among the teachers and students is involved in the teaching practice, the assessment and evaluation. This model can effectively mobilize students in response to active participation in translation practice, integration of CATTI level 3 into translation course teaching, and the cultivation of qualified translation specialists in English majors. (3) Translation teaching should take advantage of a large number of case studies, focus on topics, implement process-based teaching methods, observe the performance and progress of students during the translation process, and carry out teaching research in combination with practice (Liu, 2012, pp. 64-66). Finally, it proposes a process-based teaching model from pre-translation preparation to translation revision, changes the traditional teacher-centered teaching method to student-centered teaching, and cultivates students consciousness as interpreters.

\section{Conclusion}

CATTI participation in translation course teaching is feasible in teaching, and has two kinds of values. One is the practical application value: Firstly, the mock examinations of CATTI level 3 translation and interpretation are used to simulate the test in ability survey of the undergraduate college English majors and the effect reform in investigation; with reference to the syllabus and requirements of the CATTI level 3, this paper analyzes the translation ability of the students from the control of quantity, difficulty, test types, article types, topic types, examinees' scores, and so on. Secondly, the CATTI participation in translation course teaching cannot be only derived from the CATTI textbook module for intensive teaching and training. According to the characteristics of undergraduate education, translation teaching aims, contents, methods, and evaluation should be regarded as a whole, so as to avoid the misunderstanding of examination-oriented education. Thirdly, it has certain academic value, for taking the English majors in college undergraduates as the research object. This paper probes into the CATTI participation in translation course teaching model which shows great practical significance to merge the translation course of English major with CATTI, and enables all teachers and students to establish a democratic, harmonious, and warm teaching atmosphere while it is an effective way for students at different levels to have opportunities to participate in this cooperative teaching mode. By adopting the CATTI participation in translation 
course teaching model in practice, students' interest and enthusiasm in learning translation can be greatly enhanced, thus developing translation practical ability of the undergraduate students. As for the purpose of CATTI, translators should not be confined to be well-known specialists with basic knowledge in various fields but have one or more professional directions that he or she is particularly good at, especially the politics of the language concerned, knowledge of society and culture, etc. (Xiao, 2013, p. 17). In addition to mastering basic common sense, translators should have a good grasp of specific knowledge and the relevant background knowledge, and strive to become experts in these fields.

\section{References}

Dong, X. H. (2013). The connection between CATTI level 3 and the undergraduate course of translation: Practice and reflection-Taking the development of CATTI school-based curriculum in Northwest Normal University as an example. Chinese Translation, (2), 71.

Feng, J. Z. (2007). On the consciousness of translation professional ethics in CATTI examination system. Foreign Language Studies, (1), 53-55.

Liu, Y. (2012). Study on process-oriented translation teaching: A case study of three levels of CATTI translation practice. Education and Educational Research, (5), 64-66.

Shao, J. B. (2009). How to effectively implement participatory teaching. China Educational Technology Equipment, (23), 99.

Xiao, C. (2013). On the cultivation of translation knowledge from CATTI examination. Chinese Translators Journal, (6), 77.

Yang, Y. Z. (2011). On the three convergences of translation professional qualification (level) examination. Chinese Translation, (3), 81. 